Yukiko Takeshita $\cdot$ Norikazu Shimizu

Yukitoshi Yamaguchi · Hiroki Nakazono

Miyuki Saitou • Yoshinao Fujikawa - Tsugutoshi Aoki

\title{
Two families with Wilson disease in which siblings showed different phenotypes
}

Received: May 9, 2002 / Accepted: July 19, 2002

\begin{abstract}
We investigated two families with Wilson disease in which siblings showed different clinical phenotypes and different ages at onset. In Family 1, the second and fourth male children demonstrated onset of the neurological type of Wilson disease at 16 and 28 years of age, respectively, and the first female child developed the hepatic type at 38 years of age. In Family 2, the second male child showed neurological symptoms at 32 years of age and was diagnosed as having the hepatoneurological type of Wilson disease; then the 35-year-old first female child was found to have the hepatic type by familial screening. We performed mutation analysis of the $A T P 7 B$ gene for these patients, and found that the mutation was a compound heterozygote in both families. Previous reports of siblings with Wilson disease have shown an identical clinical phenotype and similar ages at onset. In addition, hepatic-type cases generally occur at lower ages compared with the neurological type. In the present investigation, however, younger patients showed neurological symptoms earlier than their older siblings, and clinical phenotypes differed among siblings in both families. These cases appear to be rare. Individual differences in copper accumulation in hepatic cells and intolerance to copper toxicity might be the reason for this phenomenon. Furthermore, there might be a difference in the dominance of the allele expressing ATP7B protein among these cases, resulting in different clinical phenotypes, because all patients of both families were found to be compound heterozygotes.
\end{abstract}

Key words Wilson disease $\cdot$ Sibling cases $\cdot$ ATP7B $\cdot$ Gene analysis $\cdot$ Hepatic type $\cdot$ Neurological type

Y. Takeshita $(\bowtie) \cdot$ N. Shimizu $\cdot$ Y. Yamaguchi $\cdot$ H. Nakazono M. Saitou $\cdot$ Y. Fujikawa $\cdot$ T. Aoki

Second Department of Pediatrics, Toho University School of

Medicine, Ohashi Hospital, 2-17-6 Ohashi, Meguro-ku, Tokyo

153-8515, Japan

Tel. +81-3-3468-1251, ext 3354; Fax +81-3-3468-2927

\section{Introduction}

Wilson disease is one of the typical inborn errors of copper metabolism caused by autosomal recessive heredity. The causal gene, $A T P 7 B$, is located at $13 \mathrm{q} 14.3$, and the cDNA for $A T P 7 B$ was isolated in 1993 (Yamaguchi et al. 1993; Bull et al. 1993; Petrukhin et al. 1993; Tanzi et al. 1993). The putative product protein of this gene has been thought to be a membrane protein with six copper-binding sites that belongs to a P-type ATPase family (Culotta and Gitlin 2001). Previous reports have suggested that this protein is involved in excretion of copper from hepatic cells and synthesis of active ceruloplasmin (Culotta and Gitlin 2001). Wilson disease is characterized by dysfunction of this protein, which causes abnormal accumulation of copper in various tissue, such as the liver, basal ganglia, and cornea. Major clinical signs are hepatic dysfunction, extrapyramidal dysfunction, and Kayser-Fleischer rings, as well as other clinical manifestations. Episodes of the disease also vary greatly among patients; they are classified into hepatic, neurological, fulminant, hepatoneurological, and presymptomatic types (Aoki 1984).

Despite variations in clinical symptoms, it has been thought that sibling patients usually show an identical disease type, and that the age at onset of the disease is almost identical among the siblings (Ferenci 2001). However, we here report two families with Wilson disease in which siblings showed different disease types and different ages at onset. We carried out mutation analysis of the $A T P 7 B$ gene for sibling patients. Clinical symptoms, clinical courses, and possible involvement of genetic mutations in these cases are described.

\section{Subjects and methods}

Family 1

Three sibling patients (a 52-year-old woman, a 50-year-old man, and a 42-year-old man) were investigated (Fig. 1). 
Fig. 1. Family tree (family 1). Arrow shows the proband

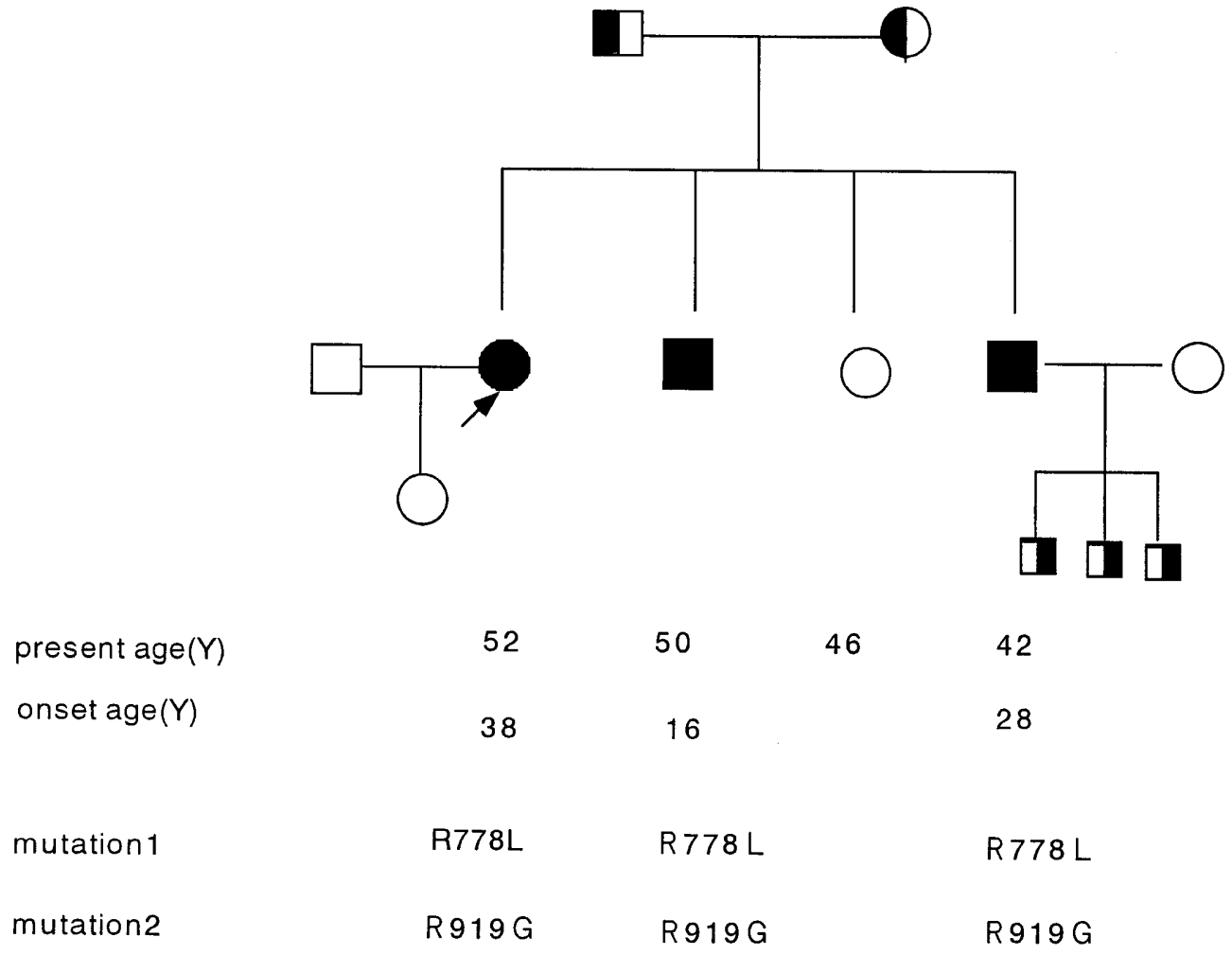

Table 1. Clinical course of Wilson disease and laboratory data (family 1)

\begin{tabular}{|c|c|c|c|c|c|c|}
\hline Case & $\begin{array}{l}\text { Onset age } \\
\text { (years) }\end{array}$ & $\begin{array}{l}\text { Liver } \\
\text { dysfunction }\end{array}$ & $\begin{array}{l}\text { Neurological } \\
\text { sign }\end{array}$ & $\begin{array}{l}\text { Serum } \\
\text { CP }(\mathrm{mg} / \mathrm{dl})\end{array}$ & Phenotype & Therapy \\
\hline 1 & 38 & $(+)$ & $(-)$ & 3.6 & Mild hepatic & $\begin{array}{l}\text { D-Penicillamine } \\
\downarrow \\
\text { Trientine }\end{array}$ \\
\hline 2 & 16 & $(-)$ & $(+)$ & Unknown & Severe neurological & D-Penicillamine \\
\hline 3 & 28 & $(-)$ & $(+)$ & 2.1 & $\begin{array}{l}\text { Neurological; } \\
\text { well managed with } \\
\text { copper-chelating agents }\end{array}$ & $\begin{array}{l}\text { D-Penicillamine } \\
\downarrow \\
\text { Trientine }\end{array}$ \\
\hline
\end{tabular}

$\mathrm{CP}$, Ceruloplasmin

Their parents were not consanguineous, and there was a clinically healthy female sibling (the third child) without biochemical abnormality (serum ceruloplasmin level, serum copper level, and urinary copper excretion were normal). The 50-year-old man, the second child, exhibited neurological manifestations such as agraphia and dysarthria at the age of 16 years. The patient was treated with Dpenicillamine, but the symptoms progressively worsened and he is currently bedridden. This patient represents the severe neurological type of Wilson disease (Table 1). The 42-year-old man (fourth child) also showed involuntary movement and agraphia at the age of 28 years. Treatment with D-penicillamine was started but then discontinued because the patient had nephrotic syndrome as an adverse reaction. D-Penicillamine was subsequently replaced by trientine when the patient was 33 years old. He has shown satisfactory improvement and is currently free from difficulty in daily living, except for mild dysdiadochokinesis (Table 1). The first child, a 52-year-old woman, was diag- nosed as having hepatic dysfunction at the age of 38 years when she was pregnant. Close examination established a final diagnosis of hepatic type of Wilson disease. Administration of D-penicillamine was started, but the drug was replaced by trientine because urinary protein was detected. The clinical course after trientine administration was excellent, and she is currently free from any clinical symptoms. She has the mild hepatic type of Wilson disease (Table 1).

\section{Family 2}

Two siblings (a 36-year-old woman and a 34-year-old man) presented with Wilson disease (Fig. 2). Their parents were not consanguineous. The third child, a 22 -year-old man, was clinically healthy and biochemically normal. His serum aspartate aminotransferase (AST), alanine aminotransferase (ALT), ceruloplasmin, and copper levels were within normal limits, and urinary copper excretion was not elevated. The 
Table 2. Clinical course of Wilson disease and laboratory data (family 2)

\begin{tabular}{|c|c|c|c|c|c|c|}
\hline Case & $\begin{array}{l}\text { Onset age } \\
\text { (years) }\end{array}$ & $\begin{array}{l}\text { Liver } \\
\text { dysfunction }\end{array}$ & $\begin{array}{l}\text { Neurological } \\
\text { sign }\end{array}$ & $\begin{array}{l}\text { Serum } \\
\text { CP }(\mathrm{mg} / \mathrm{dl})\end{array}$ & Phenotype & Therapy \\
\hline 1 & 35 & $(+)$ & $(-)$ & 3.6 & Mild hepatic & $\begin{array}{l}\text { D-Penicillamine } \\
\downarrow \\
\text { Trientine }\end{array}$ \\
\hline 2 & 32 & $(+)$ & $(+)$ & 2.0 & $\begin{array}{l}\text { Hepatoneurological; } \\
\text { well managed with } \\
\text { copper-chelating agents }\end{array}$ & $\begin{array}{l}\text { D-Penicillamine } \\
\downarrow \\
\text { Trientine }\end{array}$ \\
\hline
\end{tabular}

$\mathrm{CP}$, Ceruloplasmin

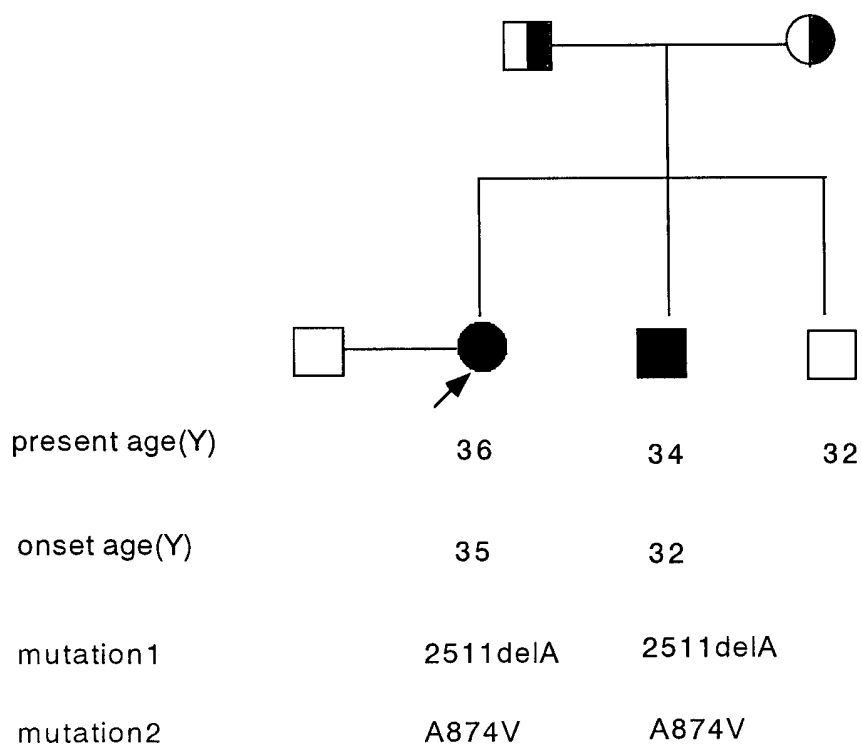

Fig. 2. Family tree (family 2). Arrow shows the proband

second male child was found to have corneal deposition at the age of 18 years at a local ophthalmic hospital, but he did not receive any treatment for the symptom. At the age of 32 years, postural tremor and consolidation signs at both wrists appeared. Diagnostic imaging demonstrated atrophy of the parenchymal brain, and abdominal ultrasonography detected cirrhosis. Subsequent close examination established a final diagnosis of the hepatoneurological type of Wilson disease (Table 2). The patient was initially treated with D-penicillamine, but because of side effects is currently being treated with trientine. The 36-year-old woman, the first child, underwent close examination after her younger brother was diagnosed as having Wilson disease. The results showed hepatic dysfunction (increase in AST and ALT), and further examination by abdominal ultrasonography also detected a mild lesion in the liver. Moreover, a decrease in the serum level of ceruloplasmin and increases in urinary copper excretion and in hepatic copper content were observed, which led to the diagnosis of hepatic-type Wilson disease. This patient demonstrates the mild hepatic type (Table 2). Treatment with D-penicillamine was started, but adverse reactions such as systematic eruption and proteinuria occurred. D-Penicillamine was therefore replaced by trientine, and the patient is currently showing satisfactory progress.
Gene analysis

Structural analysis of the causal gene $(A T P 7 B)$ for the disease was performed for three patients in family 1 and one in family 2 , after obtaining informed consent. Genomic DNA was extracted from the peripheral blood, and each exon of the $A T P 7 B$ gene was amplified by polymerase chain reaction (PCR) (Shimizu et al. 1995, 1999). Nine exons (exon 5, $8,10,11,12,13,14,16$, and 18) were selected for the first analysis on the basis of previous studies (Shimizu et al. 1995, 1999; Takeshita 2000; Yamaguchi et al. 1998; Okada et al. 2000), which had demonstrated a higher frequency of mutations in specific exons of the $A T P 7 B$ gene of Japanese patients with Wilson disease. Amplified PCR products were directly sequenced using an automated sequencer (ABI373S or 3700; ABI, CA, USA) to identify mutations.

The results indicated that family 1 was compound heterozygous for mutations R778L (exon 8) and R919G (exon 12) (Fig. 3), and family 2 for 2511delA (exon 10) and A $874 \mathrm{~V}$ (exon 11) (Fig. 4).

\section{Discussion}

The age at onset of Wilson disease varies from childhood to the fifties, and clinical expression also shows a wide variety. This disease is classified into five types by clinical course (Aoki 1984). Presymptomatic Wilson disease is detected and diagnosed during the asymptomatic period. The hepatic type demonstrates hepatic symptoms and/or liver dysfunction without any neurological symptoms. The neurological type demonstrates neurological symptoms only, without liver dysfunction. The hepatoneurological type shows both liver dysfunction and neurological symptoms during the disease course. The fulminant type is the most severe type of Wilson disease, showing sudden onset of fulminant hepatic failure and hemolytic anemia. It has been reported that hepatic disorders are major symptoms during childhood, and cranial neuropathy becomes evident during puberty and adolescence (Shimizu 2001). An epidemiological study of the disease has indicated that hepatic dysfunction appears earlier than neuropathy, and that the age at onset of the hepatic type is lower than that of the neurological type (Aoki 1984). In addition, disease types and the age of onset are known to be almost identical among sibling patients (Ferenci 2001). Thus, these two families with Wilson disease 
Fig. 3A-D. Result of gene analysis $A T P 7 B$ (family 1 ). A Electrophoregram sequencing of exon 8 (electrophoregram by ABI373S). B Electrophoregram sequencing of exon 10 (electrophoregram by ABI373S). C Conversion of the codon resulting in a missense mutation at amino acid sequence 778 (R778L). D Conversion of the codon resulting in a missense mutation at amino acid sequence 919 (R919G)
A
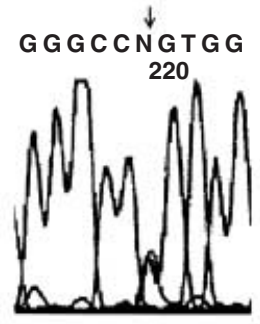

B

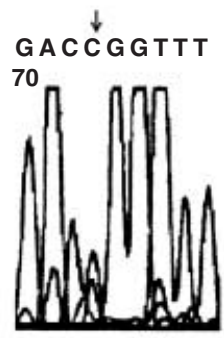

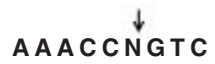

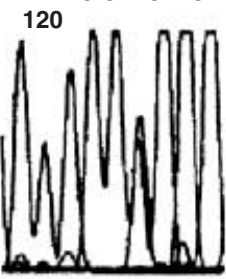

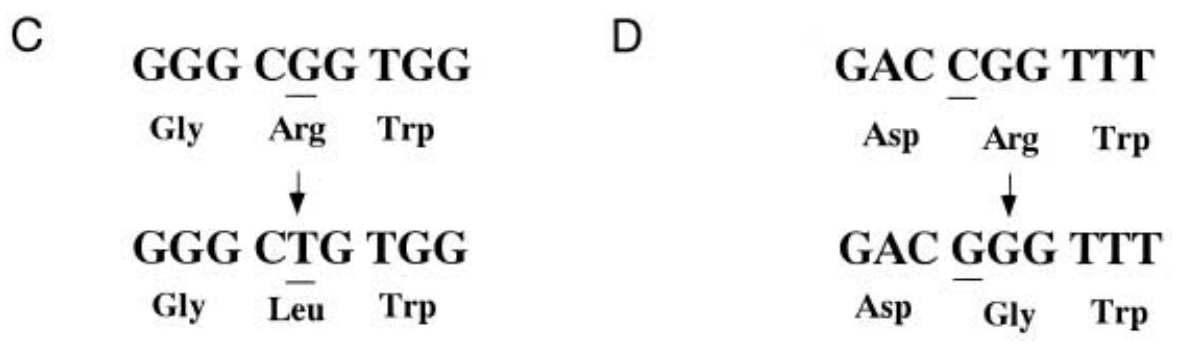

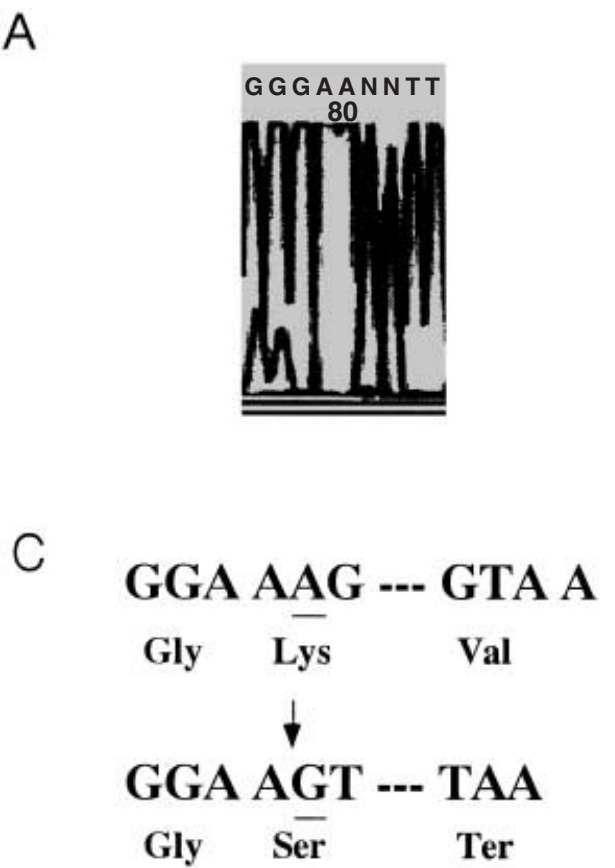

Fig. 4A-D. Result of gene analysis $A T P 7 B$ (family 2). A Electrophoregram sequencing of exon 10 (electrophoregram by ABI3700). B Electrophoregram sequencing of exon 11 (electrophoregram by ABI3700). C One-base deletion of $\mathrm{A}$ at nucleotide 2511 in exon 10 (2511delA). D Conversion of the codon resulting in a missense mutation at amino acid sequence 874 (A874V)

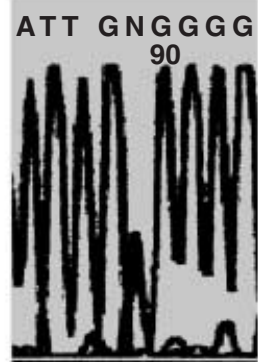

are very rare cases, demonstrating different phenotypes and different onset ages among symptomatic siblings.

In family 1 , the second and the fourth male children showed the neurological type, whereas the first female child exhibited the hepatic type 10-20 years later than the onset in her younger brothers. The age at onset of the neurological type also showed a marked difference between the two male siblings. It was suggested that the clinical courses in these siblings might be rare in Wilson disease.

Also in family 2 , the younger male child (the second child) showed neurological symptoms earlier than the first female child. It should be noted that the age at onset of the male patient was 32 years, much later than that of most neurological-type patients. Hepatic dysfunction was de- tected in the first female child, who was also diagnosed as having Wilson disease. This familial case might also be rare, and the symptoms were suggested to be rather mild in this family.

Although the exact mechanisms by which the siblings of these two families showed different clinical phenotypes and by which the neurological types occurred earlier than the hepatic types are unknown, several explanations are possible. There has been a report that the prevalence of severe hepatic dysfunction is slightly higher in females in Europe and the United States than in men (Culotta and Gitlin 2001). In this study, both women showed hepatic forms of the disease, suggesting that a gender difference is associated with the observation. However, it has been demonstrated 
that the copper content tends to be higher in patients with the neurological type of Wilson disease than in those with the hepatic type (Shimizu et al. 1998). There might be individual differences in the severity of copper accumulation in hepatic cells associated with the expression of metallothionein and in the tolerance of hepatic and/or neuronal cells against copper toxicity. The present observation that siblings showed different clinical phenotypes and different ages at onset of Wilson disease in some families is suggestive of the importance of family screening, including older siblings, if a proband is diagnosed as having Wilson disease.

To elucidate the pathology of these cases, we carried out mutation analysis of the $A T P 7 B$ gene. Both families were found to be compound heterozygotes for the mutation. The R778L mutation detected in family 1 was identical to that found in neurological patients at a significantly higher frequency, as revealed in our previous studies (Takeshita 2000; Shimizu et al. 2000). The relationship between the R919G mutation occurring on the other allele and phenotypes remains uncertain. Family 2 demonstrated a compound heterozygote of the frameshift mutation and the missense mutation. It has been suggested that frameshift mutation is more frequently detected in the hepatic type (Shimizu et al. 2000). These results raise the possibility that the dominance of the allele expressing the ATP7B protein differs among patients, which might result in different clinical phenotypes. Functional and anatomical analyses on the expressed ATP7B protein are necessary to elucidate the relationship between genetic mutations and clinical phenotypes of the disease. In addition, the structure of the ATP7B protein, its ability to transport copper, and its localization within hepatic cells should be clarified in future studies. Furthermore, the association of the mutant proteins with various in vivo dysfunctions should be examined to clarify the pathological mechanisms in Wilson disease.

Acknowledgments The authors thank Dr. Mitsuru Siba and Dr. Masahiro Doi for providing patient samples and medical information. We are also grateful to Professor Hiroyuki Shimatake and Professor Hiromichi Hemmi (Department of Molecular Biology, Toho University School of Medicine) for excellent technical assistance. This work was supported in part by a Grant-in-Aid-for Scientific Research(C) (project number: 10670764) from the Ministry of Education, Science, Sports, and Culture of Japan.

\section{References}

Aoki T (1984) Wilson disease, 1st edn. Seiwashotenn, Tokyo

Bull PC, Thomas GR, Rommens JM, Forbes JR, Cox DW (1993) The Wilson disease gene is a putative copper transporting P-type ATPase similar to the Menkes gene. Nat Genet 5:327-337

Culotta VC, Gitlin JD (2001) Disorder of copper transport. In: Scriver CR, Beaudet AL, Sly WS, Valle D (eds) The metabolic and molecular basis of inherited disease. McGraw-Hill, New York, pp 31053126

Ferenci P (2001) Wilson disease. Indian J Gastroenterol 20:C71-C78

Okada T, Shiono Y, Hayashi H, Satoh H, Sawada T, Suzuki A, Takeda Y, Yano M, Michitaka K, Onji M, Mabuchi H (2000) Mutational analysis of ATP7B and genotype-phenotype correlation in Japanese with Wilson's disease. Hum Mutat 15:454-462

Petrukhin K, Fischer SG, Pirastu M, Tanzi RE, Chernov I, Devoto M, Brzustwics LM, Cayanis E, Vitale E, Russo JJ, Matseoane D, Boukhgalter B, Wasco W, Figus AL, Loudianos J, Cao A, Sternlieb I, Evgrafov O, Parano E, Pavone L, Warburton D, Ott J, Penchaszadeh GK, Scheinberg IH, Gilliam TC (1993) Mapping, cloning and genetic characterization of the region containing the Wilson disease gene. Nat Genet 5:338-343

Shimizu N (2001) Wilson disease. Nippon Rinsho 59(Suppl 8):383-389 Shimizu N, Kawase C, Nakazono H, Hemmi H, Shimatake H, Aoki T (1995) A novel RNA splicing mutation in Japanese patients with Wilson disease. Biochem Biophys Res Commun 217:16-20

Shimizu N, Suzuki M, Yamaguchi Y, Aoki T, Matsuda I, Arima M (1998) A nation-wide survey for neurologic and hepato-neurologic type of Wilson disease. No To Hattatsu 28:391-397

Shimizu N, Nakazono H, Takeshita Y, Ikeda C, Fujii H, Watanabe A, Yamaguchi Y, Hemmi H, Shimatake H, Aoki T (1999) Molecular analysis and diagnosis in Japanese patients with Wilson's disease. Pediatr Int 41:409-413

Shimizu N, Takeshita Y, Hemmi H, Shimatake H, Aoki T (2000) Study of genotype phenotype correlation for Wilson disease. J Jpn Soc Mol Med 37:62

Takeshita Y (2000) Regional differences of ATP7B mutations and relationship between mutations and serum ceruloplasmin levels in Japanese patients with Wilson disease. JJPS 104:711-716

Tanzi RE, Petrukhin K, Chernov I, Pellequer JL, Wasco W, Ross B, Romano DM, Parano E, Pavone L, Brzustowics LM, Devoto M, Peppercorn J, Bush AI, Sternlieb I, Pirastu M, Gusella JF, Evgrafov O, Penchaszadeh GK, Honig B, Edelman IS, Soares MB, Scheinberg IH, Gilliam TC (1993) The Wilson disease gene is a copper transporting ATPase with homology to the Menkes disease gene. Nat Genet 5:344-350

Yamaguchi A, Matsuura A, Arashima S, Kikuchi Y, Kikuchi K (1998) Mutation of $A T P 7 B$ gene in Wilson disease in Japan: identification of nine mutations and lack of clear founder effect in a Japanese population. Hum Mutat (Suppl 1):320-322

Yamaguchi Y, Heiny ME, Gitlin JD (1993) Isolation and characterization of a human liver cDNA as a candidate gene for Wilson disease. Biochem Biophys Res Commun 197:271-277 